\title{
COMPARISONS AND CONTRASTS BETWEEN THE REPOPULATIONS FOLLOWING THE EARLY TOARCIAN (EARLY JURASSIC) AND CENOMANIAN-TURONIAN (MID-CRETACEOUS) MASS EXTINCTIONS
}

HARRIES, Peter J., Dept. of Geology, Univ. of South Florida, Tampa, FL 33617-5200, U.S.A.; LITTLE, Crispin T. S., Palaeontology Dept., The Natural History Museum, London, UK

One of the most elusive aspects of mass extinctions has been reasonable comparisons between various events in the geologic record. This has been complicated by the differing forcing mechanisms, durations, and magnitudes of the various events. The Early Toarcian (ETo) and the Cenomanian-Turonian (Ce-Tu) mass extinctions afford an excellent opportunity to attempt this type of investigation. There are several reasons for this: 1) for both extinctions, anoxia played a dominant role in forcing the extinction; 2) both extinction intervals show a step-wise to gradational pattern; 3 ) the overall paleoenvironmental setting was fairly similar. Both events occurred just prior to peak sea-level highstand that resulted in widespread epeiric seaways and both sequences are dominated by organic-rich shales and limestones/calcareous concretions. Finally, 4) the extinction intensities of the two events are identical: $26 \pm 4$ at the generic level as determined by Sepkoski (1989).

The faunal data discussed here are from high-resolution studies of the ETo and $\mathrm{Ce}-\mathrm{Tu}$ sediments from the Cleveland (UK) and Western Interior (USA) Basins, respectively. Although these are not global databases, they are also representative of data from other regions. The framework for this comparison is the repopulation model presented in Kauffman and Erwin (1995). This model subdivides a mass extinction into three intervals: extinction, survival, and recovery. For both the ETo and Ce-Tu events, these intervals are readily defineable from the available stratigraphic ranges. In both events, inarticulate brachiopods are disaster species, although in the ETo event they occur near the upper part of the survival interval, whereas in the Ce-Tu event their maximum abundance is close to the base of the survival interval. The early disaster form that appear directly above the ETo extinction are Nucinella sp. A. Within the survival interval, the dominant taxa are primarily inoceramids, other "flat clams" or "paper pectinids", and ostreid epifaunal bivalves. Most of these are either opportunists or ecological generalists. A slight difference exists in the ammonite patterns. For the ETo event, they display rapid evolutionary rates through the early phase of the survival interval, whereas for the Ce-Tu event, they are very rare during this portion.

For both mass extinction events, the recovery interval is characterized by an overall increase in diversity and the reappearance of more "normal" taxa suites suggesting an amelioration of conditions. Although only the lower portion of the recovery interval was sampled for the ETo event, it nevertheless shows a marked increase in diversity of bivalves, ammonites, and belemnites and the initial reappearance of brachiopods and crinoids. The Ce-Tu recovery also involves a pronounced increase in diversity in bivalves and ammonites as well as the re-establishment of communities more typical of background. Both repopulations also show that the gastropods are the slowest to recover, although the reason for this remains equivocal.

\section{REFERENCES}

Kauffman, E. G., and Erwin, D. H., 1995, Surviving mass extinctions: Geotimes, v. 40, 14-17.

Sepkoski, J. J., Jr., 1989, Periodicity in extinction and the problem of catastrophism in the history of life: Journal of the Geological Society of London, v. 146, p. 7-19. 